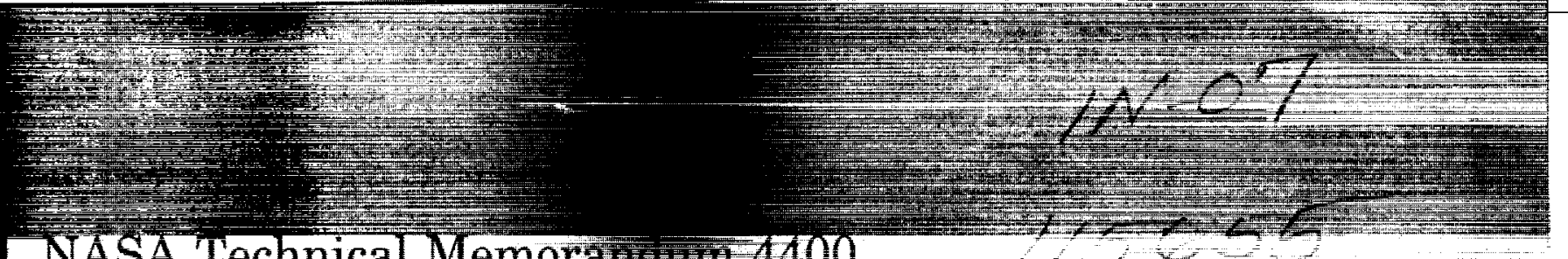

NASA Technical Memoratione 4100

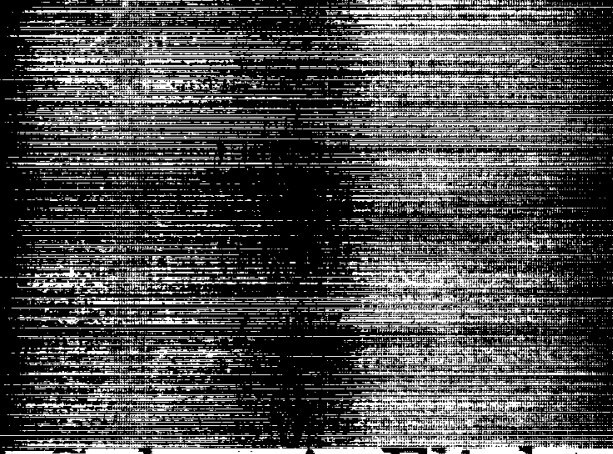

ESubsonic Flight Test Evaluation

of a Performance Seeking Control

Agorithm on an R-15 Airplane

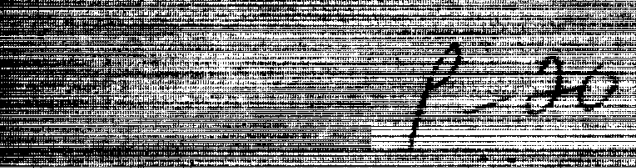

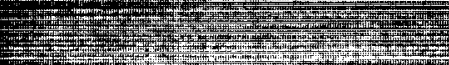

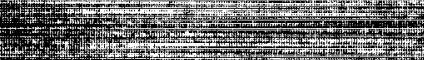


and

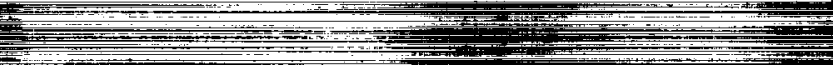

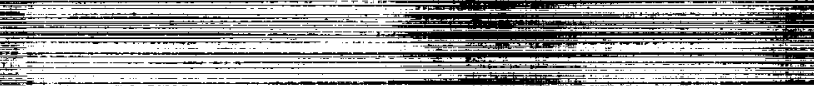

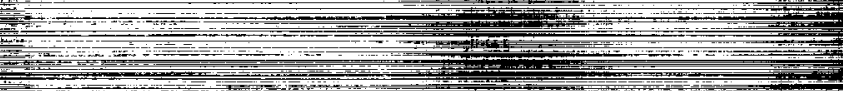

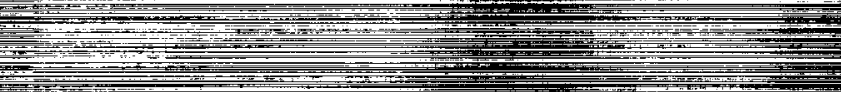

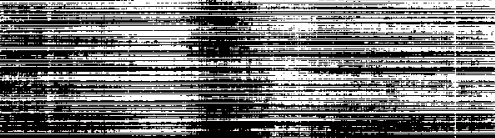

$+x$

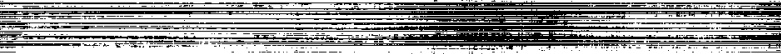

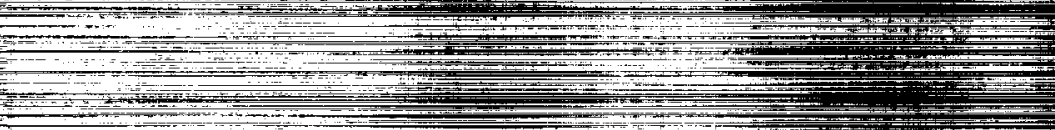


NASA Technical Memorandum 4400

\section{Subsonic Flight Test Evaluation of a Performance Seeking Control Algorithm on an F-15 Airplane}

Glenn B. Gilyard and John S. Orme

Dryden Flight Research Facility

Edwards, California

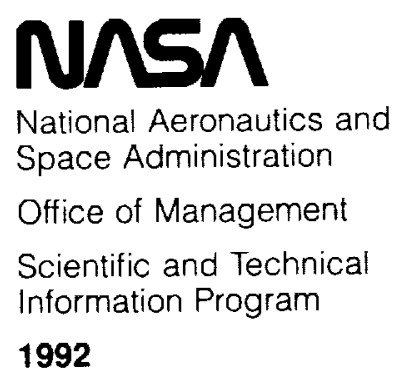





\title{
SUBSONIC FLIGHT TEST EVALUATION OF A PERFORMANCE SEEKING CONTROL ALGORITHM ON AN F-15 AIRPLANE
}

\author{
Glenn B. Gilyard* and John S. Orme ${ }^{* *}$ \\ NASA Dryden Flight Research Facility \\ Edwards, California
}

\begin{abstract}
The subsonic flight test evaluation phase of the NASA F-15 (powered by F100 engines) performance seeking control program was completed for singleengine operation at part- and military-power settings. The subsonic performance seeking control algorithm optimizes the quasi-steady-state performance of the propulsion system for three modes of operation. The minimum fuel flow mode minimizes fuel consumption. The minimum temperature mode extends turbine life by decreasing the fan turbine inlet temperature. The maximum thrust mode maximizes thrust at military power. Decreases in thrust-specific fuel consumption of 1 to 2 percent were measured in the minimum fuel flow mode; these fuel savings are significant especially for supersonic cruise aircraft. Decreases of up to approximately $100^{\circ} \mathrm{R}$ in fan turbine inlet temperature were measured in the minimum temperature mode. Temperature reductions of this magnitude would more than double turbine life if inlet temperature was the only life factor. Measured thrust increases of up to approximately 15 percent in the maximum thrust mode cause substantial increases in aircraft acceleration. The system dynamics of the closed-loop algorithm operation were good. The subsonic flight phase has validated the performance seeking control technology, which can significantly benefit the next generation of fighter and transport aircraft.
\end{abstract}

\section{Nomenclature}

AAHT area adder high-pressure turbine component deviation parameter, in ${ }^{2}$

$A J$ nozzle throat area, in ${ }^{2}$

\footnotetext{
*Aerospace Engineer. Member AIAA.

** Aerospace Engineer.

Copyright (C) 1992 by the American Institute of Aeronautics and Astronautics, Inc. No copyright is asserted in the United States under Title 17, U.S. Code. The U.S. Government has a royalty-free license to exercise all rights under the copyright claimed herein for Governmental purposes. All other rights are reserved by the copyright owner.
}

$A J N L \quad$ effective nozzle throat area, in ${ }^{2}$

$B L D \quad$ bleed air flow, $\mathrm{lb} / \mathrm{sec}$

CEM compact engine model

CIM compact inlet model

CIVV compressor inlet variable guide vane angle, deg

CPSM compact propulsion system model

DEEC digital electronic engine control

$D E H P T$ high-pressure turbine component deviation parameter, percent

$D E L P T \quad$ low-pressure turbine component deviation parameter, percent

$D W F A N$ change in fan airflow component deviation parameter, lb/sec

$D W H P C \quad$ change in high-pressure compressor airflow component deviation parameter, lb/sec

EPR engine pressure ratio, PT6/PT2

F

steady-state-variable model sensitivity matrix

FNP net propulsive force, lbf

FTIT fan turbine inlet temperature, ${ }^{\circ} \mathrm{R}$

$h$

$H P X \quad$ power extraction, hp

$M$

Mach number

MIL military

N1 fan rotor speed, rpm

$N 1 C 2 \quad$ fan rotor speed, corrected to station 2 temperature, rpm

N2 compressor rotor speed, rpm

$P B \quad$ static burner pressure, $\mathrm{lb} / \mathrm{in}^{2}$

PLA power lever angle, deg

PSC performance seeking control 


\begin{tabular}{|c|c|}
\hline PSM & propulsion system matrix \\
\hline$P T$ & $\begin{array}{l}\text { total pressure, } \mathrm{lb} / \mathrm{in}^{2} \text { (used with engine } \\
\text { location suffixes, list follows) }\end{array}$ \\
\hline$R C V V$ & rear compressor variable vane angle, deg \\
\hline$S M F$ & fan stall margin, percent \\
\hline$S M H C$ & $\begin{array}{l}\text { high-pressure compressor stall margin, } \\
\text { percent }\end{array}$ \\
\hline SSVM & steady-state-variable model \\
\hline SVM & state-variable model \\
\hline$T M T$ & composite turbine metal temperature, ${ }^{\circ} \mathrm{R}$ \\
\hline$T S F C$ & $\begin{array}{l}\text { thrust-specific fuel consumption, } \\
\qquad W F / F N P, \mathrm{hr}^{-1}\end{array}$ \\
\hline$T T$ & $\begin{array}{l}\text { total temperature, }{ }^{\circ} \mathrm{R} \text { (used with } \\
\text { suffixes, list follows) }\end{array}$ \\
\hline$u$ & $\begin{array}{l}\text { vector of control variables in the state- } \\
\text { variable model }\end{array}$ \\
\hline$u_{i}$ & $\begin{array}{l}\text { vector of control variables in the compact } \\
\text { inlet model }\end{array}$ \\
\hline$u_{m}$ & $\begin{array}{l}\text { vector of control variables in the steady- } \\
\text { state-variable model }\end{array}$ \\
\hline$u_{p}$ & $\begin{array}{l}\text { vector of control variables in the linear } \\
\text { programming problem }\end{array}$ \\
\hline$W A C C$ & DEEC calculated airflow, lb/sec \\
\hline$W C F A N$ & corrected fan airflow, lb/sec \\
\hline$W C H P C$ & $\begin{array}{l}\text { corrected high-pressure compressor } \\
\text { airflow, lb/sec }\end{array}$ \\
\hline$W F$ & gas generator fuel flow, lb/hr \\
\hline$x$ & $\begin{array}{l}\text { vector of state variables in the state- } \\
\text { variable model }\end{array}$ \\
\hline$y$ & $\begin{array}{l}\text { vector of output variables in the state- } \\
\text { variable model }\end{array}$ \\
\hline$y_{i}$ & $\begin{array}{l}\text { vector of output variables in the compact } \\
\text { inlet model }\end{array}$ \\
\hline$y_{m}$ & $\begin{array}{l}\text { vector of output variables in the steady- } \\
\text { state-variable model }\end{array}$ \\
\hline$y_{p}$ & $\begin{array}{l}\text { vector of output variables in the linear } \\
\text { programming problem }\end{array}$ \\
\hline
\end{tabular}

Suffixes, PW1128 engine station numbers, Fig. 2

$\begin{array}{ll}2 & \text { fan inlet } \\ 2.5 & \text { compressor inlet } \\ 3 & \text { compressor discharge } \\ 4 & \text { high-pressure turbine inlet } \\ 4.5 & \text { low-pressure turbine inlet }\end{array}$

$$
\begin{array}{ll}
6 & \text { afterburner inlet } \\
7 & \text { nozzle throat }
\end{array}
$$

\section{Introduction}

The application of digital engine control has opened up the possibility of significantly improving the performance of the aircraft-propulsion system by applying optimal control algorithms to the integrated aircraftpropulsion system. The development and implementation of this technology will provide a wide range of benefits in both civil and military applications by extending engine life and maximizing fuel efficiency and thrust.

To develop this optimal performance technology base, NASA Dryden Flight Research Center (Edwards, CA), McDonnell Aircraft Company (St. Louis, MO), and Pratt \& Whitney (West Palm Beach, FL) have developed and flight-tested an adaptive performance seeking control (PSC) system with the objective of optimizing the quasi-steady-state performance of the F-15 propulsion system. ${ }^{1,2}$ The PSC system was developed with the following optimization modes: minimum fuel flow at constant thrust, minimum turbine temperature, and maximum thrust.

Subsonic flight testing of the PSC algorithm at NASA Dryden covered the three PSC optimization modes at part-power and military- (MIL) power conditions. Preliminary results were previously reported. ${ }^{3}$ This paper describes the algorithm, reviews the flight test program including maneuvers used, and presents quantitative flight results of the benefits of the various modes. Additional results from the current flight test program covering comparisons of PSC operation with predictions, operation of the real-time in-flight estimation process, in-flight identification, and ground test results are presented in Refs. 4-7.

\section{Airplane and Engine Description}

The PSC system was implemented on the NASA F-15 research airplane (Fig. 1), which is a highperformance aircraft capable of speeds in excess of Mach 2. The NASA F-15 is powered by two F100 derivative (PW1128) afterburning turbofan engines. ${ }^{8}$ The aircraft was modified with a digital electronic engine control (DEEC) system.

The PW1128 engine ${ }^{9}$ is a low-bypass ratio, twin spool, afterburning turbofan technology demonstrator, derived from the F100-PW-100 engine. The engine is controlled by a full-authority DEEC system that is similar to the current production F100 engine controller. The DEEC provides open-loop scheduling of compressor inlet variable vanes (CIVV) and rear compressor variable vanes $(R C V V)$ positions based on 
rotor speeds. Closed-loop feedback control of corrected fan speed (N1C2) and engine pressure ratio (EPR) is provided through the fuel flow $(W F)$ and nozzle area $(A J)$, respectively. The DEEC software was modified to accommodate PSC trim commands; however the normal DEEC control loops (i.e., $N 1 C 2$ and EPR) were not modified. The DEEC trim commands for subsonic, nonafterburning conditions are perturbations on $C I V V, R C V V, N 1 C 2$, and $A J$.

Two engines with different performance levels-one refurbished and one degraded-were evaluated during the subsonic phase of the program. Initial PSC system testing used a recently refurbished engine installed in the right side of the aircraft. All algorithm verification and early testing were done with this engine. All of the PSC design work used models of a nominal engine, which represents an engine as it comes off the production line or, in our case, the refurbished engine. Near the end of the subsonic flight test program, a very degraded engine was installed in the left side of the aircraft. This engine was degraded to such an extent that it was estimated to have as few as five flight hours remaining on it. The main degradation was in the high-pressure rotor; both the compressor and turbine had significant efficiency degradation, estimated to be approximately 2 percent in each flow path cross-sectional area.

\section{Instrumentation}

Figure 2 shows a diagram of the PW1128 engine with the locations of the DEEC sensors and additional research instrumentation noted. Fan airflow (WCFAN) and engine face total pressure (PT2) are independently modeled by both the DEEC and PSC control laws. The PSC algorithm was developed using only conventional DEEC-instrumented parameters as inputs, and the algorithm estimates other necessary parameters. The engine instrumentation and PSC parameters were recorded at $20 \mathrm{~Hz}$.

In addition to the basic engine parameters, the challenging nature of the technology being demonstrated required the recording of many internal algorithm variables. These additional variables provided for detailed real-time and postflight analysis of the algorithm. More than 200 internal parameters were recorded at a rate of 100 samples/sec.

Figure 3 presents a flow diagram of the algorithm. The control law consists of estimation, modeling, and optimization processes. In the Kalman-filter estimator (discussed later), the inputs, outputs, and residuals were recorded. At the compact propulsion system modeling stage (discussed later), all the estimated inlet and engine parameters were recorded. In addition to temperatures, pressures, and control positions, such estimated parameters as stall margins, thrust, and drag components were recorded. In the optimization phase (discussed later), the operating condition constraints, optimal solution, and linear programming health status condition codes were recorded. Finally, the actual commands that were sent to the engine through the DEEC were recorded.

The airdata used for the PSC system were obtained from the F-15 production side probes. The algorithm corrects the data for position error and location effects. The airdata were recorded at $20 \mathrm{~Hz}$. All data were recorded on a pulse code modulation system.

\section{Performance Seeking Control Law Algorithm}

The PSC algorithm estimates optimal control settings for an adaptive, onboard propulsion system model. The algorithm flow diagram (Fig. 3) consists of estimation, modeling, and optimization processes. The estimation process uses a Kalman filter to estimate five component deviation parameters. These parameters account for the off-nominal operation of the engine during flight. They are related to the changes in efficiency of the low- and high-pressure turbine (DELPT and DEHPT, respectively), the changes in fan and high-pressure compressor airflow (DWFAN and $D W H P C$, respectively), and a high-pressure turbine area adder $(A A H T)$.

The second step formulates the compact propulsion system model (CPSM) to estimate unmeasured engine outputs required to obtain an optimal solution. The component deviation parameters estimated in the first step are input to the CPSM. These parameters shift the model to reflect the actual operating condition of the engine required by the follow-on optimization. Flight measurements are used to look up model data and as direct inputs to the Kalman filter and CPSM. $\overline{\mathrm{A}}$ propulsion system matrix (PSM), which is linear, is derived from the nonlinear CPSM.

The optimal solution of the PSM within the defined constraints is obtained using a linear programming algorithm. The true optimal engine operating point requires iterating on the CPSM modeling and linear programming optimization a specified number of times because of the nonlinearity of the CPSM. The iterative process is referred to as inner looping. The component deviation parameters are assumed constant during the inner looping. Once the inner loop is completed, the engine interface logic determines the trims required to achieve the current optimal operating conditions.

\section{Kalman Filter}

The first step in the estimation process identifies the off-nominal characteristics of the engine when operating at or near steady-state conditions. This is done by 
estimating five component deviation parameters with a Kalman filter. These parameters are used to adjust the nominal CPSM to more closely match the actual engine operating condition. A state-variable model (SVM) is used in the design and implementation of the Kalman estimator. It is a piecewise linear model covering the entire range of engine operation at $0.9 \mathrm{Mach}, 30,000-\mathrm{ft}$ altitude, and standard day conditions. It consists of a state-space perturbation model, an associated table of steady-state trim values for all engine variables in the model, and some extended calculations. The state $(x)$, control $(u)$, and output $(y)$ vectors are defined as follows:

$$
\begin{aligned}
x= & {[N 1 \text { N2 TMT DEHPT DELPT DWFAN }} \\
& D W H P C \text { AAHT }]^{T} \\
u= & {\left[\begin{array}{ll}
W F \text { AJ CIVV RCVV HPX BLD }
\end{array}\right]^{T} } \\
y= & {\left[\begin{array}{lll}
P T & \text { PTA TT4.5 N1 N2 }
\end{array}\right]^{T} }
\end{aligned}
$$

The values for the fan rotor speed $(N 1)$, compressor rotor speed (N2), and composite turbine metal temperature $(T M T)$ are the original states of the engine model. These three states are then augmented in the Kalmanfilter estimator by the five component deviation parameters so that these deviation parameters could be estimated. Values for the following output and control variables are taken directly from flight data: $N 1, N 2$, burner pressure $(P B), T T 4.5, P T 6, W F, A J, C I V V$, and $R C V V$. The $P T 4$ is modeled as a function of $P B$; horsepower extraction, $H P X$, is scheduled as a function of $N 2$; and bleed airflow, $B L D$, is scheduled as a function of Mach and altitude. Additional engine and flight parameters are used indirectly by the Kalmanfilter algorithm for correcting the engine data and calculating other engine variables. The measured and calculated variables are corrected to the SVM design condition of Mach 0.9 and 30,000-ft altitude. Additional information on the development and implementation of the Kalman filter can be found elsewhere. ${ }^{5,10}$

\section{Compact Propulsion System Model}

The second step in the estimation process is formulation of the CPSM. The CPSM combines two smaller compact models-the compact engine model (CEM) and the compact inlet model (CIM)-that together model the propulsion system and form the basis for the optimization process.

\section{Compact Engine Model}

The CEM consists of a linear steady-state variable model (SSVM) and follow-on nonlinear calculations. The SSVM has a design condition of Mach 0.9, 30000- $\mathrm{ft}$ altitude but has been shifted to a sea-level static reference condition for implementation. The SSVM is of the form

$$
y_{m}=[F] u_{m}
$$

where $F$ is the sensitivity matrix and $u_{m}$ and $y_{m}$ represent the SSVM control and output vectors respectively. They are defined to be

$$
\begin{aligned}
u_{m}= & {[W F \text { PT6 CIVV RCVV HPX BLD DEHPT }} \\
& \text { DELPT DWHPC DWFAN AAHT }]^{T} \\
y_{m}= & {[N 1 \text { N2 AJ PT2.5 PT4 TT2.5 TT3 TT4 TT4.5 }} \\
& \text { TT6 WCFAN WCHPC }]^{T}
\end{aligned}
$$

The SSVM uses engine measurements for the following variables: $W F, P T 6, C I V V$, and $R C V V$. Horsepower extraction and bleed airflow are again derived from schedules. The measured inputs are corrected to the SSVM sea-level static reference condition using correction factors that are a function of $P T 2$ and $T T 2$. The Kalman-filter estimates of the component deterioration parameters are input to the SSVM calculation as part of the input vector. The SSVM provides estimates of the $y_{m}$ variables at sea-level static conditions. These estimates are then 'uncorrected' to the original flight condition for use in the subsequent nonlinear CEM calculations.

Following completion of the linear SSVM calculation, the nonlinear CEM estimates are calculated at the original flight condition. These variables include gross thrust, ram drag, nozzle drag, high-pressure compressor stall margin, effective nozzle throat area $(A J N L)$, net propulsive force $(F N P)$, fan stall margin $(S M F)$, $P T 7$, and $T T 7$. The nonlinear calculations use a combination of analytical equations and empirically derived data tables. They are based upon both measured engine variables and SSVM values. If an SSVM variable is measured, the flight measurement (not the estimated value) is then used in the nonlinear calculations. The nonlinear calculations for several of these variables, $S M F, A J N L, F N P$, and high-pressure compressor stall margin $(S M H C)$, are linearized with respect to $W F, P T 6, C I V V$, and $R C V V$ in real time. The partials generated are used in the follow-on optimization process. Additional information on the CEM calculations is available in Ref. 3.

\section{Compact Inlet Model}

At subsonic flight conditions, the nominal inlet schedules were determined to be already optimal, and as such, inlet geometry is not included in the PSC algorithm at subsonic conditions. Additional information on the CIM is available in Nobbs et al. ${ }^{11}$

\section{Optimization Process}

The subsonic phase of the PSC algorithm seeks to optimize the combined performance of the engine. The 
PSC system uses linear-programming techniques to determine the optimal engine trims for the defined engine-inlet model and its related constraints. The linear-programming optimization is performed on the PSM, which is a linearized formulation of the CPSM. The linear-programming problem determines the optimum set of control deflections and output variables, subject to a specific set of constraints.

The PSC system has three primary modes of operation: minimum fuel flow at constant $F N P$, minimum fan turbine inlet temperature $(F T I T)$, and maximum thrust. The minimum fuel flow mode is primarily designed for cruise conditions, whereas the minimum FTIT and maximum thrust modes are primarily intended for use during accelerating flight conditions. The minimum fuel flow at constant FNP mode is designed to effectively minimize thrust-specific fuel consumption (TSFC). The minimum FTIT mode is designed to lower the FTIT while maintaining $F N P$ levels during both cruise and accelerating flight conditions. (During cruise conditions, FNP is assumed constant and constrained to a constant reference value; during changing flight conditions, the $F N P$ is assumed constant during each optimization but is not constrained to a constant reference value.) The maximum thrust mode is designed to maximize thrust at MIL power.

The PSM forms the basis of the linear-programming problem. Linear models from the CEM and CIM are integrated to form the PSM. The PSM control and output vectors, $u$ and $y$, are defined to be:

$$
\begin{aligned}
u_{p}= & {[W F \text { PT6 CIVV RCVV }]^{T} } \\
y_{p}= & {[N 1 C 2 N 2 \text { PB WCFAN TT3 FTIT SMF }} \\
& S M H C A J \text { FNP }]^{T}
\end{aligned}
$$

Each control and output variable has associated constraints used in the formulation of the linearprogramming problem. The constraints are functions of engine hardware, empirical data, and the desired goal of the optimization.

\section{Digital Electronic Engine Control Interface and Supervisory Logic}

In addition to the PSC control law, the PSC system includes the necessary logic to interface with the DEEC as well as logic to monitor the engine operation. The DEEC interface logic calculates the trims required to achieve the PSC optimal engine operating condition. These DEEC trim commands are perturbations on $C I V V, R C V V, N 1 C 2$, and $A J$. The supervisory logic provides an additional margin of safety during flight test. The engine is monitored to protect against adverse situations such as fan stalls by modifying the trims when necessary. Further, it contains maneuver accommodation logic that will suspend PSC operation, if warranted, and revert to baseline engine operation. The DEEC applies the trims to the engine while verifying that the engine will not exceed rotor speed, turbine temperature, and combustor pressure limits.

The development of a PSC algorithm for the supersonic flight regime is presented by Nobbs et al, ${ }^{11}$ and a discussion of performance benefits achievable with in-flight adaptive optimization is presented by Tempelman and Gallops. ${ }^{12}$

\section{Flight Test Program}

The subsonic PSC flight test program was conducted at the NASA Dryden Flight Research Facility during 1990-91 and covered 10 months. The flight test activity was a joint effort by NASA, McDonnell Aircraft Company, and Pratt \& Whitney. The subsonic flight test series was in turn broken into three phases: initial algorithm validation, baseline algorithm evaluation, and evaluation of a very degraded engine. All flight testing to date has consisted of a single engine being in a PSC mode at any given time. Simultaneous PSC operation of both engines was not possible, but the PSC system could be selected on either engine. One-engine testing was not a disadvantage since most PSC system benefits are on a per-engine basis. The single-engine operation was actually more of an advantage for initial PSC flight evaluation since the flight safety issues for a single-engine research effort are much less than for two engines. (The nontest engine was in a standard F-15 configuration and as such, in a worst-case test engine scenario, baseline single-engine capability was available.) The flexibility afforded by reduced safety concerns for one-engine test flight operation was a major benefit in the PSC algorithm troubleshooting, modification, and evaluation process.

\section{Initial Algorithm Validation}

The objective of the initial flight test evaluation of the PSC algorithm was to ensure that the algorithm was behaving as predicted and that unmodeled flight dynamics of the aircraft did not affect PSC mode operation. This phase (and also the following phase) was conducted using the refurbished engine. The nontest engine was a standard F100 nonresearch engine. A functional checkout of the PSC system's capabilities was conducted first, followed by preliminary evaluations of the various PSC modes. This initial phase was also used to develop, evaluate, and refine the flight test procedures for the following phases. This test phase required four dedicated flights.

\section{Primary Algorithm Evaluation}

The objective of this phase was to obtain quantitative flight test results for the refurbished engine. This phase was not initiated until the identified problems of 
the previous phase were satisfactorily resolved so that they would not be an issue when interpreting flight results. The quantitative flight testing began at the primary design condition of $30,000 \mathrm{ft}$. The SVM and SSVM used in the algorithm were also developed at this flight condition, and as such, the algorithm operation is expected to be the best at this flight condition. Flight testing then proceeded to $45,000 \mathrm{ft}$, which is near the best cruise performance of the aircraft. Flight testing was concluded at $15,000 \mathrm{ft}$, which is an important flight region for high-performance aircraft maneuvering. This flight phase required 10 dedicated flights.

\section{Degraded Engine Evaluation}

The objective of this phase was to obtain quantitative flight test results for a very degraded engine. A comparison of these results with those of the refurbished engine would thus provide an additional indication of the robustness of the PSC algorithm. Testing covered the same flight conditions as those used for the primary algorithm evaluation tests. To obtain the best quality data for comparison purposes, most of the maneuvers were done in pairs; that is, a maneuver with the degraded engine was then repeated on the same flight with the refurbished engine. This was required to minimize effects caused by such things as atmospheric conditions, flight conditions, and even piloting technique (project flying rotated among three pilots). A number of parametric studies were also performed during this test phase; the most important one was an evaluation of biases on the measured parameters used in the PSC algorithm. What effect a measurement bias on a key parameter has on the algorithm is a difficult issue since no independent means exist to determine what the bias levels are. ${ }^{5}$ This flight phase consisted of 20 dedicated flights.

\section{Flight Test Maneuvers}

The PSC evaluation process collected flight data primarily from trimmed cruise flight (wings-level, constant speed, and altitude) and constant altitude accelerations, which ranged from $M \approx 0.50$ to $M \approx 0.95$.

\section{Cruise Flight}

Stabilized cruise flight conditions were used to collect data for all three PSC modes. The maneuver consisted of stabilizing the aircraft at the desired Mach and altitude flight conditions with the PSC system disengaged. Altitude was normally controlled with an autopilot mode, although the pilot was capable of similar manual flightpath control performance with head-up display commands. Constant velocity flight conditions were maintained through pilot-commanded throttle inputs to the nontest engine.
The test engine conditions normally were set to a desired power lever angle (PLA) and the engine allowed to stabilize (rotor speed, temperature, and pressure) before starting the data collection. The algorithm performs its calculations, which include the determination of optimal commands. These commands, however, are not sent to the engine until the PSC system is engaged, but are available for evaluation and comparison purposes only.

In addition to the requirement for the flight conditions and engine conditions to stabilize, there was also the requirement to wait for the Kalman filter of the PSC algorithm to stabilize. Although four of the five efficiency parameters converged rather quickly, $D W F A N$ quite often required an additional 30 to $60 \mathrm{sec}$ to settle out. Once everything had stabilized, data with the PSC system disengaged were collected for approximately $2 \mathrm{~min}$; then the PSC system was engaged and data collection continued for an additional $2 \mathrm{~min}$. If additional parametric studies were being conducted, this sequence continued with only the PSC system configuration being changed.

In the minimum fuel flow mode, data were typically collected with the test engine at $40^{\circ}, 50^{\circ}, 60^{\circ}, 70^{\circ}$, and MIL $\left(\approx 85^{\circ}\right)$ PLA settings. All cruise testing for the maximum thrust and minimum FTIT modes was with the test engine in MIL power. At some altitudes with this high-power setting, idle throttle on the nontest engine was not sufficient to keep the aircraft from accelerating, and in these cases, the speedbrake was also deployed as required.

\section{Acceleration}

Accelerating flight conditions were used to collect data for the maximum thrust and minimum FTIT modes of the PSC system. The maneuver nominally consisted of accelerating the aircraft from $M \approx 0.50$ to $M \approx 0.95$ at constant altitude flight conditions. All of these accelerations were conducted with the test engine in MIL power. The nontest engine was either in idle power $\left(\approx 20^{\circ}\right.$ PLA) or MIL power; this engine was not throttled by the pilot during accelerations. With the nontest engine in idle, the acceleration progressed more slowly and as such the algorithm was nearer to a steady-state condition. The MIL-power setting was used on the nontest engine at conditions where the acceleration progressed too slowly or the aircraft could not accelerate to $M \approx 0.95$. (No part-power throttle positions were used for accelerations since the throttle position could not be duplicated for the following run.) Although acceleration times are drastically affected by the nontest engine throttle position, the primary results presented are for the thrust or temperature changes of the test engine and these are 
not affected by the nontest engine. Altitude was normally controlled by the pilot using head-up displays.

The maneuver sequence started with the PSC system disengaged and the pilot acquiring the desired initial Mach number. The test engine was then put to MIL power, which required the pilot to enter a turn to keep from accelerating prematurely. The test engine stabilized fairly rapidly, but the acceleration was not initiated until the Kalman-filter portion of the algorithm was also stabilized; then the aircraft was rolled wingslevel and accelerated at constant altitude to $M \approx 0.95$, at which point the maneuver was terminated. The aircraft was decelerated and the maneuver repeated with the PSC system engaged.

Acceleration maneuvers were performed for maximum thrust and minimum FTIT modes of the PSC system. At 45,000 - $\mathrm{ft}$ altitude, aircraft excess thrust is so low that the maneuver was started at $M \approx 0.75$ and terminated at $M \approx 0.93$ due to the drag rise.

\section{System Flight Test Capabilities}

The PSC system was designed with a high level of capability and flexibility to conduct parametric studies of the PSC algorithm. Most changes required to conduct desired parametric studies were invoked in real time through pilot entries on a cockpit keyboard. A selected list of these capabilities follows:

\section{Real-Time PSC System Capabilities}

1. PSC system engaged or disengaged

\section{Right- or left-engine select}

\section{Real-time or preflight estimation}

\section{PSC optimization with or without vanes}

\section{Unbiased or biased measurement input}

In addition to real-time changes that the pilot could make, many other control-law changes were possible between flights without a new control-law release. Other, more complex flight code changes could be made, verified, delivered, and installed in as little as 3 days. The overall system flexibility was a major attribute in the PSC flight test program.

\section{Flight Test Results}

The three PSC modes have undergone subsonic flight testing. Maneuvers were flown on the F-15 to evaluate PSC system performance benefits and the dynamic algorithm behavior. The engine flight data presented in this paper were obtained from both a refurbished engine and a degraded engine.

\section{Minimum Fuel Flow Mode}

The minimum fuel flow mode is designed to minimize fuel flow while maintaining constant $F N P$ (effectively reducing $T S F C$ ) during cruise flight conditions. The maneuvers flown consisted of flying at stabilized flight conditions. The minimum fuel flow mode was evaluated at high subsonic Mach numbers and at 15,000-, 30,000 , and $45,000-\mathrm{ft}$ altitudes. Flight data were collected for a range of PLA conditions.

Figure 4 presents the results for a typical minimum fuel flow mode maneuver at a flight condition of Mach 0.88 and $45,000 \mathrm{ft}$. Time histories are presented for performance parameters $(M, F T I T, F N P$, and $T S F C$ ), control variables $(W F, C I V V, R C V V$, and $A J)$, and engine operating parameters (EPR, $S M F$, and the DEEC-calculated airflow, WACC). The PSC algorithm was not engaged from 0 to approximately 120 sec. The steady-state value of TSFC with the PSC system disengaged was approximately 0.99 . The PSC system was engaged from $120 \mathrm{sec}$ through the end of the run. The PSC algorithm held FNP to within \pm 2 percent of the initial value after the PSC system was engaged. The steady-state TSFC with the PSC system engaged was approximately 0.97 , a nearly $2-$ percent improvement on fuel consumption. The fuel reduction (at constant thrust) was achieved by opening $R C V V 2^{\circ}$ to its limit $\left(4^{\circ}\right)$ and closing $A J 40 \mathrm{in}^{2}$ to its minimum nozzle area $\left(388 \mathrm{in}^{2}\right)$. The $C I V V$ is on its limit throughout the run. This resulted in the engine operating with both reduced $W A C C$ and $S M F$. This flight condition is near the optimal minimum $T S F C$ condition for the baseline aircraft.

A comparison of measured and predicted $T S F C$ savings which resulted from the PSC system is presented in Fig. 5 as a function of test-engine power setting. Data were collected at $15,000-, 30,000$, and $45,000-\mathrm{ft}$ altitudes for both the refurbished and degraded engines. The $T S F C$ savings are in general relatively small. The calculation of $T S F C$ is especially sensitive to the parameters that define it (TSFC= $W F(F N P)$ and the relatively short run of data collected. In spite of the scatter, the $T S F C$ savings are clearly established ranging from a few tenths of a percent at the lowest power settings to one to one-and-onehalf-percent savings at the MIL-power setting. The flight data are in good agreement with the predictions at the high PLAs but are noticeably lower than predictions at $50^{\circ}$ PLA. In general, the best improvements appear to be at 45,000- $\mathrm{ft}$ altitude. Based on the general similarity of the data, it is clear that the PSC algorithm has the ability to adapt to the specific health state of the engine.

Although not large, the TSFC reductions could significantly reduce takeoff gross weight or increase 
range when considering long-range cruise segments, as might be encountered for a second-generation supersonic transport.

\section{Minimum Fan Turbine Inlet Temperature Mode}

The minimum FTIT mode increases engine life by decreasing FTIT while maintaining a constant $F N P$ level during both cruise and accelerating flight conditions. The maneuvers flown consisted of flying at cruise and accelerating flight conditions. The minimum FTIT mode was evaluated over a range of high subsonic Mach numbers and at 15,000-, 30,000-, and 45,000- $\mathrm{ft}$ altitudes.

Figure 6 presents a typical time history comparison of several performance and engine variables for back-toback accelerations from Mach 0.5 to 0.95 (at $30,000 \mathrm{ft}$ ) with the PSC system engaged and disengaged. Time histories are presented for performance parameters (altitude $(h), M, F N P$, and $F T I T$ ), control variables ( $W F, C I V V, R C V V$, and $A J$ ), and engine operating parameters (EPR, $S M F$, and $W A C C$ ). The FTIT reduction gradually increases to $80^{\circ} \mathrm{R}$ as Mach 0.70 is approached, then gradually decreases to a reduction of $45^{\circ} \mathrm{R}$ as Mach 0.90 is reached. The PSC algorithm held FNP to nearly the same value for both of the runs. The FTIT reduction was achieved by increasing EPR and reducing airflow by closing $C I V V$ from its maximum limit and closing $A J$ to its minimum limit throughout the run and an incremental opening in $R C V V$ to its limit during the early portion of the run.

A comparison of measured and predicted FTIT reductions as a result of the PSC system is presented in Fig. 7 for the engine at a MIL-power setting. Data were collected at $15,000-30,000$, and $45,000-\mathrm{ft}$ altitudes for both the refurbished and degraded engines. The FTIT reductions are large at $45,000 \mathrm{ft}$, ranging from in excess of $100^{\circ} \mathrm{R}$ at the lower Mach numbers and diminishing slightly as transonic Mach numbers are approached. The measured and predicted FTIT reductions agree well for all flight conditions.

To put these temperature reductions in perspective, every $70^{\circ} \mathrm{R}$ reduction will double turbine life caused by temperature effects. ${ }^{3}$ These benefits are very important especially at high-power settings where the engine operates near its temperature limit. At $30,000 \mathrm{ft}$, the FTIT reductions range from 45 to $80^{\circ} \mathrm{R}$ at the higher subsonic Mach numbers. Although less than those at $45,000 \mathrm{ft}$, these reductions are still significant in terms of extending engine life. The FTIT reductions at 15,000 ft are at best small, and in some cases small increases in temperatures were observed. These small temperature reductions at lower altitudes are consistent with predictions. ${ }^{3}$ The variations in the data at $15,000 \mathrm{ft}$ also reflect the resolution, accuracy, and repeatability of the closed-loop PSC algorithm throughout the flight envelope.

Although the minimum fuel flow and minimum FTIT mode optimal solutions are arrived at independently, the resulting solutions are similar; that is, minimum fuel flow results in lower FTIT and minimum FTIT results in lower fuel flow.

\section{Maximum Thrust Mode}

The maximum thrust mode is designed to maximize $F N P$ at MIL power. Both acceleration and cruise maneuvers were used for evaluation. The maximum thrust mode was evaluated using subsonic accelerations at altitudes of $15,000,30,000$, and $45,000 \mathrm{ft}$.

Figure 8 presents a typical time history comparison of several performance and engine variables for back-to-back accelerations from Mach 0.5 to 0.95 (at $30,000 \mathrm{ft}$ ) with the PSC system engaged and disengaged. Time histories are presented for performance parameters ( $M$, ALT, $F N P$, and FTIT), control variables $(W F, C I V V, R C V V$, and $A J)$, and engine operating parameters (EPR, $S M F$, and $W A C C$ ). The PSC algorithm increased $F N P$ by approximately 11percent above the nominal thrust level over the entire Mach range. The thrust increase was achieved by a large increase in EPR and a small reduction in airflow by increasing $W F$ and closing $A J$ to its limit which resulted in FTIT and $S M F$ reaching their limits. The $R C V V$ also opened to its limit during the lower Mach range.

A comparison of measured and predicted thrust increases produced by the PSC system is presented in Fig. 9 for the engine at a MIL-power setting. Data were collected at 15,000-, 30,000-, and 45,000-ft altitudes in accelerating and cruise conditions for the refurbished and degraded engines. For the refurbished engine at 30,000 ft, thrust increases average approximately 11 percent as Mach increases from 0.60 to 0.90 and compare very well with predictions. The degraded engine has significantly less thrust-increase capability and diminishes with increasing Mach number. This level of thrust increases requires the engine to operate hotter. For the refurbished engine, FTIT in general is below the engine operating limit with the PSC system engaged or disengaged. However, the degraded engine is operating hotter over the flight envelope to achieve a defined thrust level. In particular, with the PSC system engaged, the FTIT limit is generally restricting the amount of additional thrust increase.

The 45,000-ft thrust increase levels and trends are similar to those at $30,000 \mathrm{ft}$. At the 45,000 - $\mathrm{ft}$ flight condition not as much data were collected since the aircraft cannot stabilize at the lower Mach numbers. The data are quite limited at $15,000 \mathrm{ft}$; however the 
thrust increases for the degraded engine at the lower Mach numbers are low because of the engine temperature limit being reached. At $M=0.90$, the refurbished engine has a thrust improvement of 15 percent, while the degraded engine has approximately half that amount. In general, the maximum thrust mode has performed well, demonstrating significant thrust increases at MIL power.

The single-engine flight test evaluation for the minimum fuel flow and minimum FTIT modes completely characterizes the benefits of the PSC algorithm since they are engine improvements as opposed to net aircraft improvements. However, for the maximum thrust mode, two-engine performance is of importance since net aircraft performance is a primary interest. Figure 10 presents one-engine and two-engine results, with the two-engine results extrapolated from the oneengine flight data. As indicated, the two-engine, PSCengaged acceleration time reduction is nearly twice that for the one-engine case. The PW1128 engines are one of a kind; the identified benefits are obviously a function of its hardware and controller design.

\section{Concluding Remarks}

The initial flight test evaluation phase of the performance seeking control algorithm was completed for one-engine subsonic part-power and military-power operation. The three performance seeking control modes were evaluated at $15,000,30,000$, and $45,000 \mathrm{ft}$. The performance seeking control system was designed with a high level of capability and flexibility to conduct parametric studies of the performance seeking control algorithm. Most changes required to conduct desired parametric studies were invoked in real time through pilot entries on a cockpit keyboard. The overall system flexibility was a major attribute in the performance seeking control flight test program.

Flight results indicate that substantial benefits were obtained from the performance seeking control algorithm. In the maximum thrust mode, increases in thrust of up to 15 percent at typical combat-type flight conditions were identified. Thrust increases of this magnitude could be useful in a combat situation. The minimum fan turbine inlet temperature mode demonstrated temperature reductions exceeding $100^{\circ} \mathrm{R}$ at high altitudes. If temperature were the only factor affecting engine life, these reductions would more than double engine life. The minimum fuel flow mode results demonstrated fuel consumption decreases of up to 2 percent.

The single-engine subsonic flight phase has validated the performance seeking control technology objectives.
Based on flight test results, it is clear that performance seeking control technology can provide significant benefits to the next generation of fighter and supersonic transport aircraft.

\section{References}

${ }^{1}$ Tich, E.J., Shaw, P.D., Berg, D.F., Adhibatla, S., Swan, J.A., and Skira, C.A., "Performance Seeking Control for Cruise Optimization in Fighter Aircraft," AIAA-87-1929, June 1987.

${ }^{2}$ Smith, R.H., Chisholm, J.D., and Stewart, J.F., "Optimizing Aircraft Performance with Adaptive, Integrated Flight/Propulsion Control," ASME-90-GT-252, June 1990.

${ }^{3}$ Lambert, H.H., Gilyard, G.B., Chisholm, J.D., and Kerr, L.J., Preliminary Flight Evaluation of an Engine Performance Optimization Algorithm, NASA TM4328, 1991.

${ }^{4}$ Chisholm, J.D., "In-Flight Optimization of the Total Propulsion System," AIAA-92-3744, July 1992.

${ }^{5}$ Orme, John S. and Gilyard, Glenn B., "Subsonic Flight Test Evaluation of a Propulsion System Parameter Estimation Process for the F100 Engine," AIAA92-3745, July 1992.

${ }^{6}$ Bushman, M. and Gallops, G.W., "In-Flight Performance Identification Capability of an Adaptive Engine Model," AIAA-92-3746, July 1992.

${ }^{7}$ Conners, T.R., "Thrust Stand Evaluation of Engine Performance Improvement Algorithms in an F-15 Airplane," AIAA-92-3747, July 1992.

${ }^{8}$ Digital Electronic Engine Control (DEEC) Flight Evaluation in an F-15 Airplane, Proceedings of a minisymposium held at NASA Dryden Flight Research Facility, Edwards, California, May 25-26, 1983, NASA CP-2298.

${ }^{9}$ Myers, L.P. and Burcham, F.W., Jr., Preliminary Flight Test Results of the F100 EMD Engine in an F-15 Airplane, NASA TM-85902, 1984.

${ }^{10}$ Luppold, R.H., Gallops, G., Kerr, L., and Roman, J.R., "Estimating In-Flight Engine Performance Variations Using Kalman Filter Concepts," AIAA-89-2584, July 1989.

${ }^{11}$ Nobbs, S.G., Jacobs, S.W., and Donahue, D.J., "Development of the Full-Envelope Performance Seeking Control Algorithm," AIAA-92-3748, July 1992.

${ }^{12}$ Tempelman, W.G. and Gallops G.W., "Performance Benefits of Adaptive In-Flight Propulsion Sys tem Optimization," AIAA-92-3749, July 1992. 


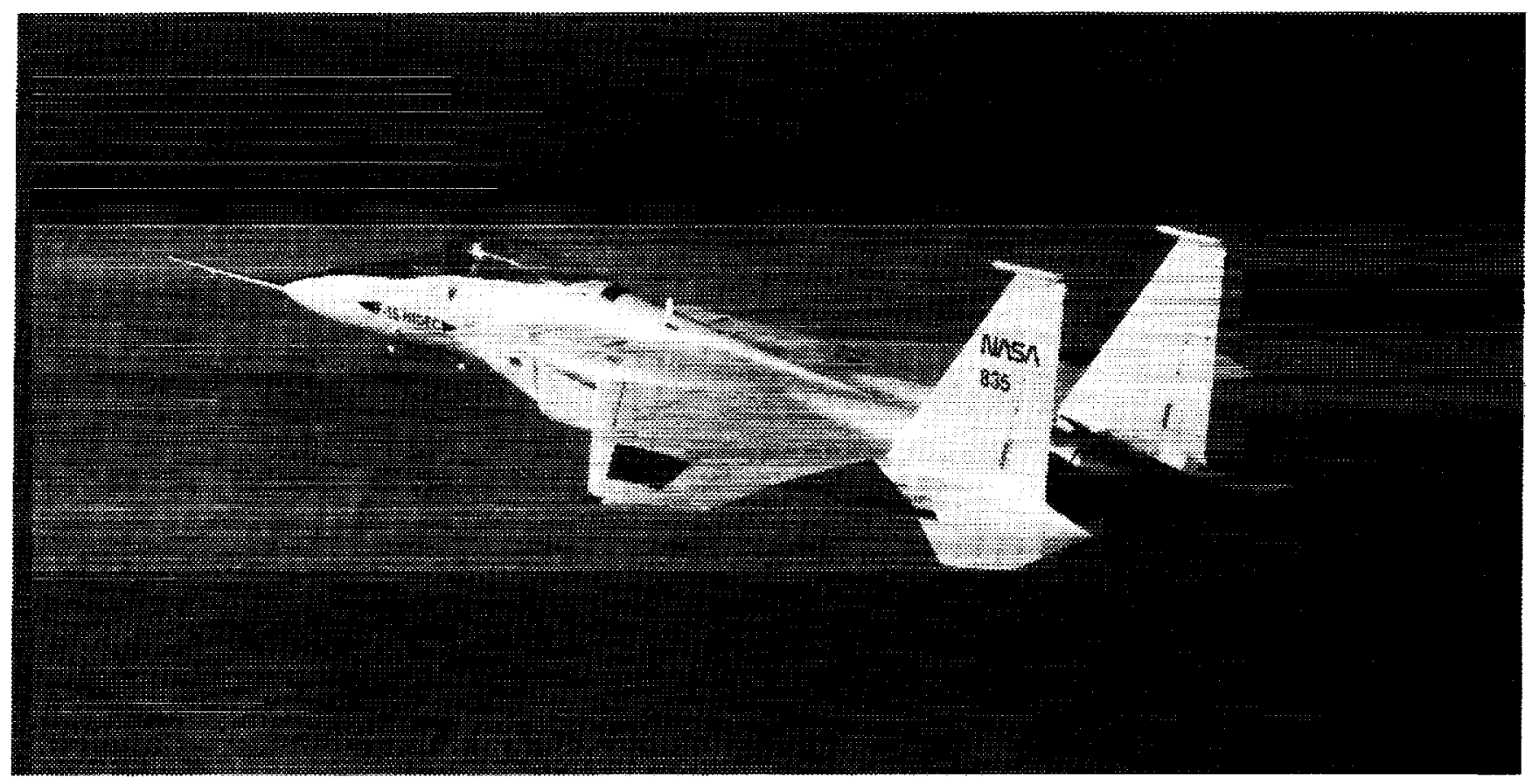

EC90 312-11

Fig. 1. The F-15 aircraft.

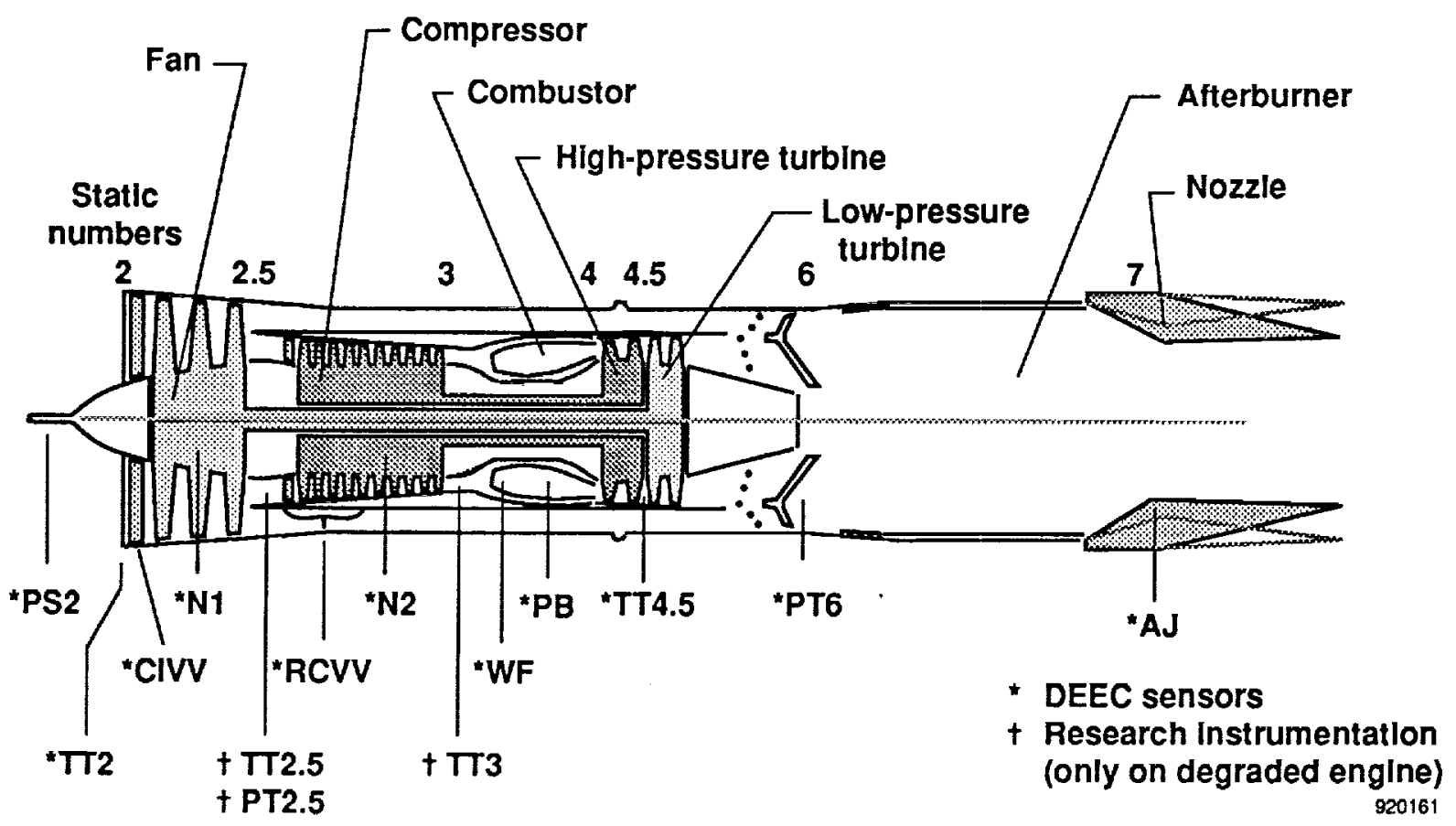

Fig. 2. The PW1128 engine, sensor, and parameter locations. 


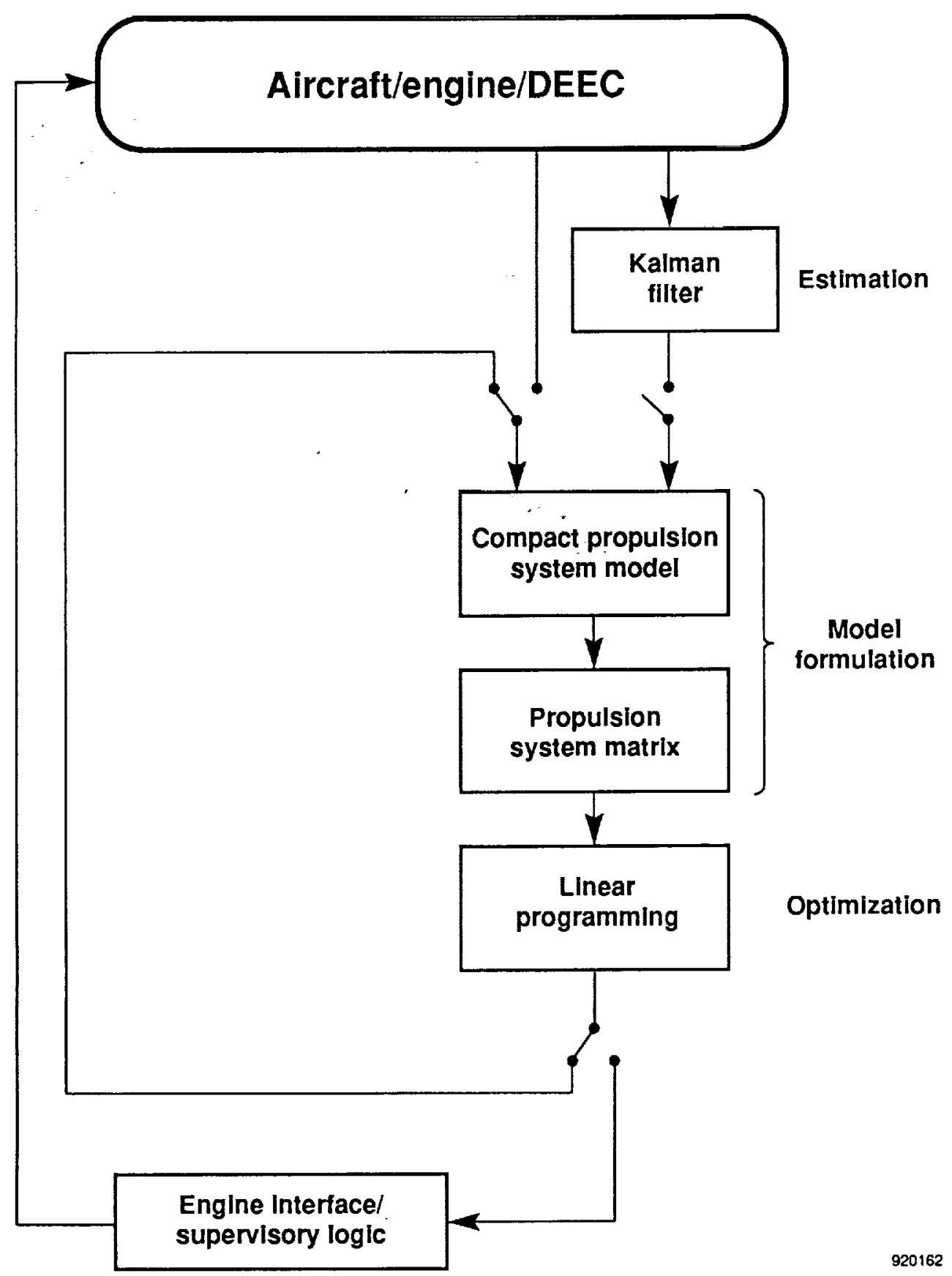

Fig. 3. Performance seeking control flow diagram. 


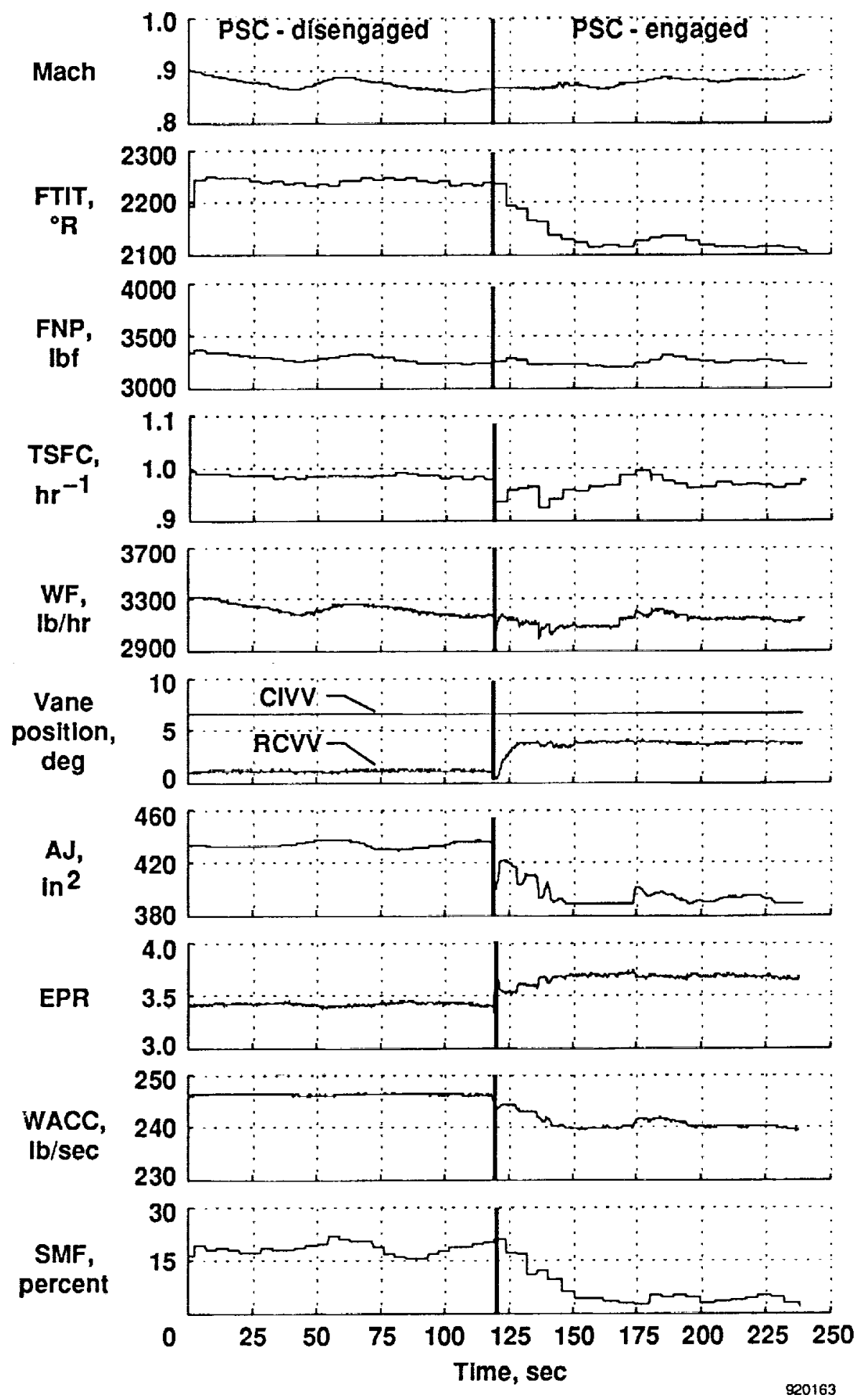

Fig. 4. Typical engine parameter time histories for minimum fuel flow mode evaluation $(45,000 \mathrm{ft}$, degraded engine, military power). 


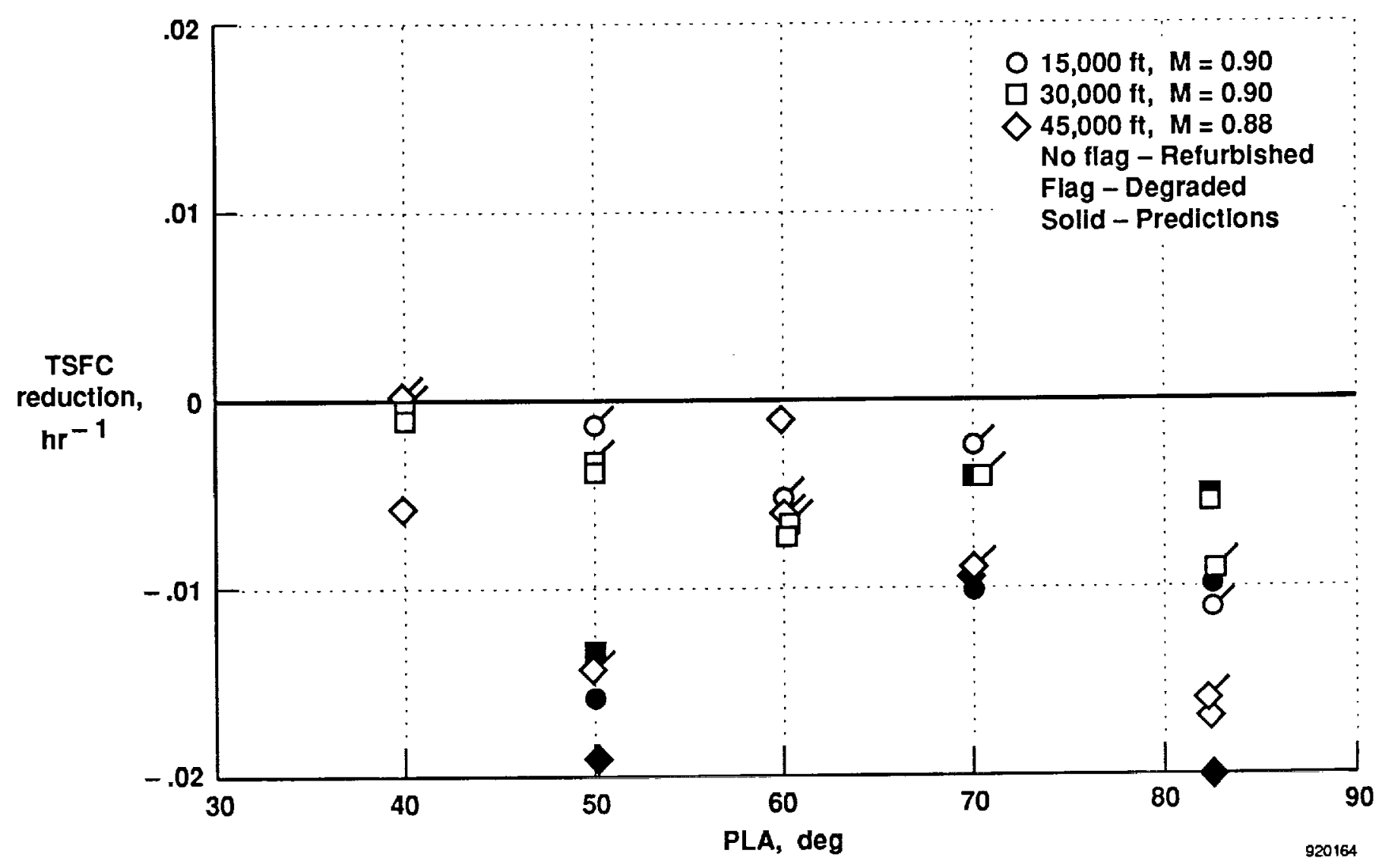

Fig. 5. Predicted and measured thrust specific fuel consumption reductions produced by performance seeking control as a function of power setting and altitude. 


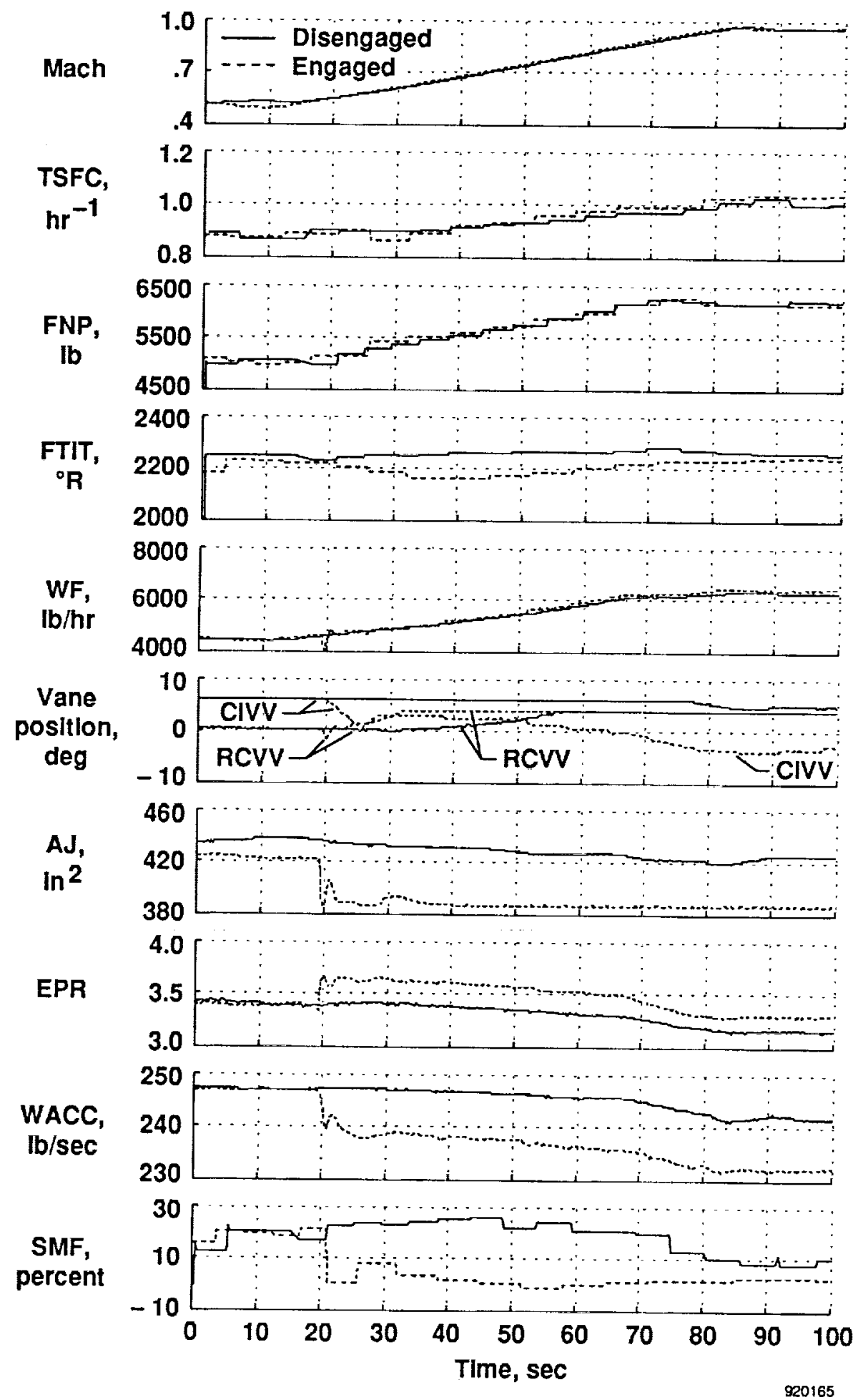

Fig. 6. Typical engine parameter time histories for minimum fan turbine inlet temperature mode evaluation $(30,000 \mathrm{ft}$, refurbished engine, military power). 


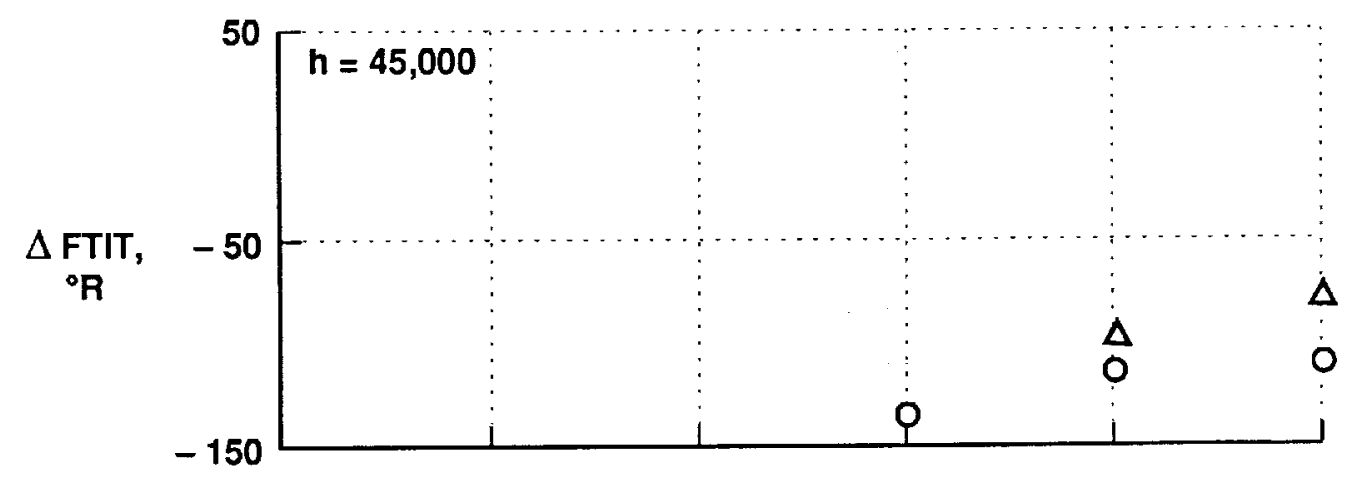

O Degraded engine

$\triangle$ Predictions
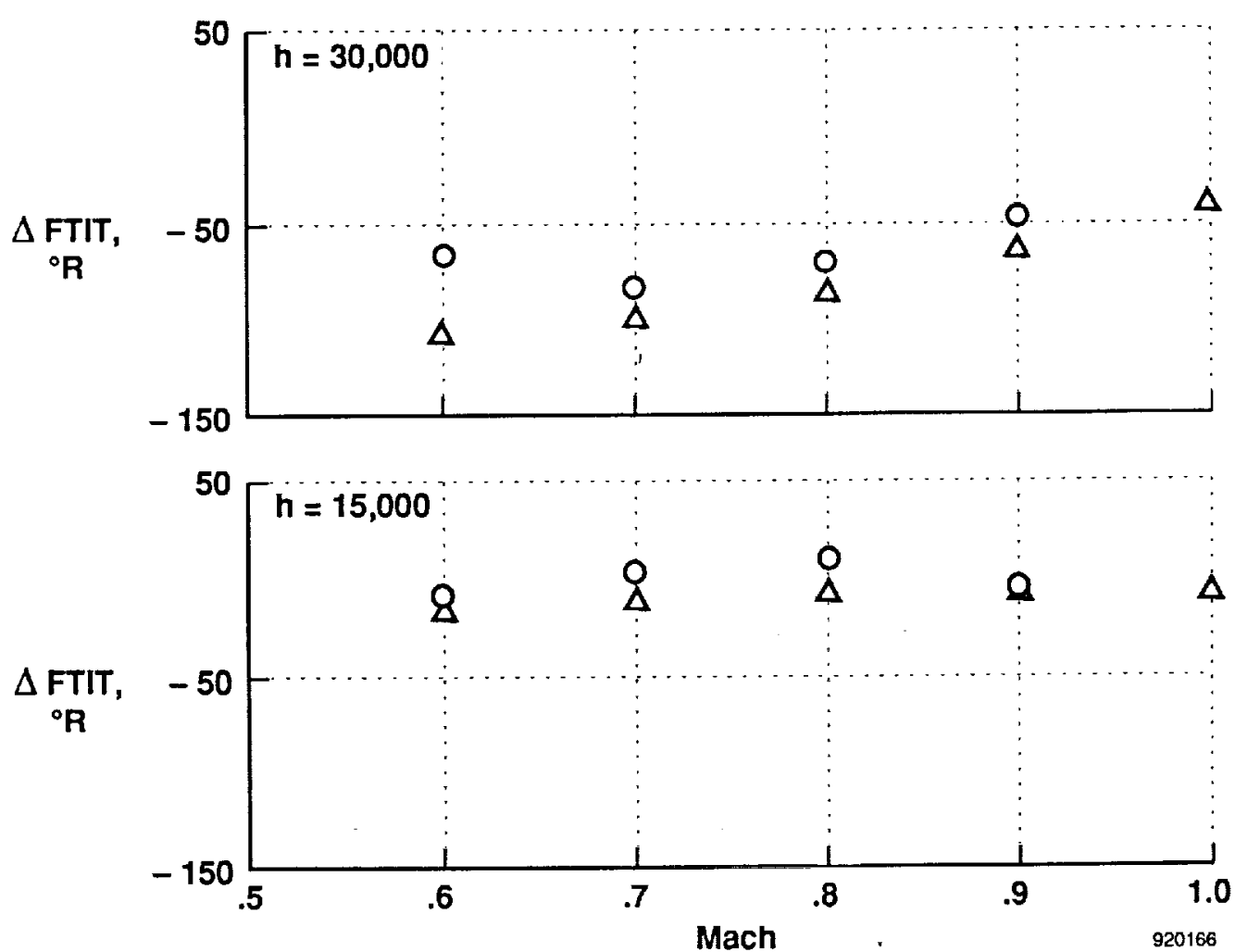

Fig. 7. Predicted and measured fan turbine inlet temperature decreases produced by performance seeking control as a function of flight condition. 


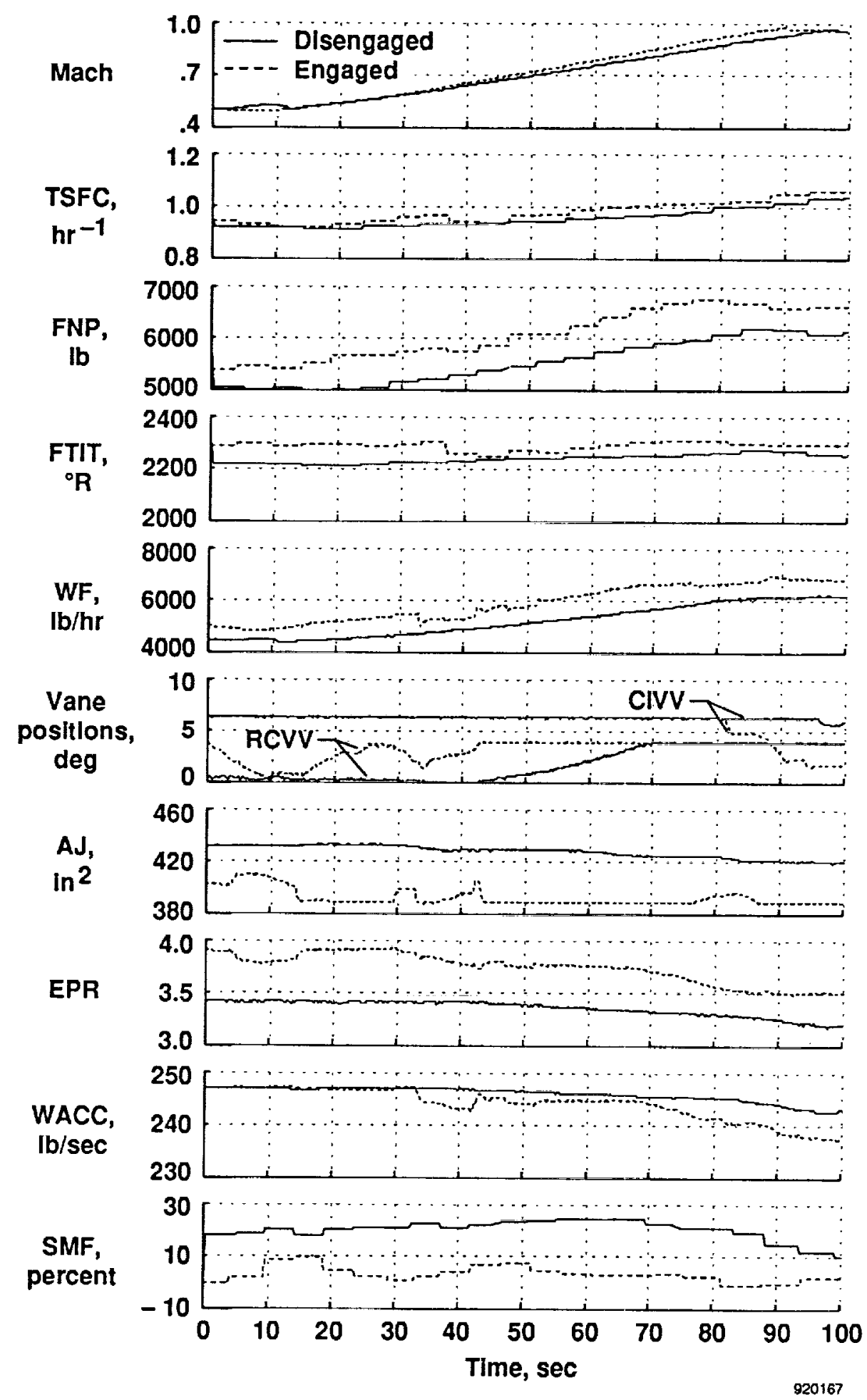

Fig. 8. Typical engine parameter time histories for maximum thrust mode evaluation $(30,000 \mathrm{ft}$, refurbished engine, military power). 

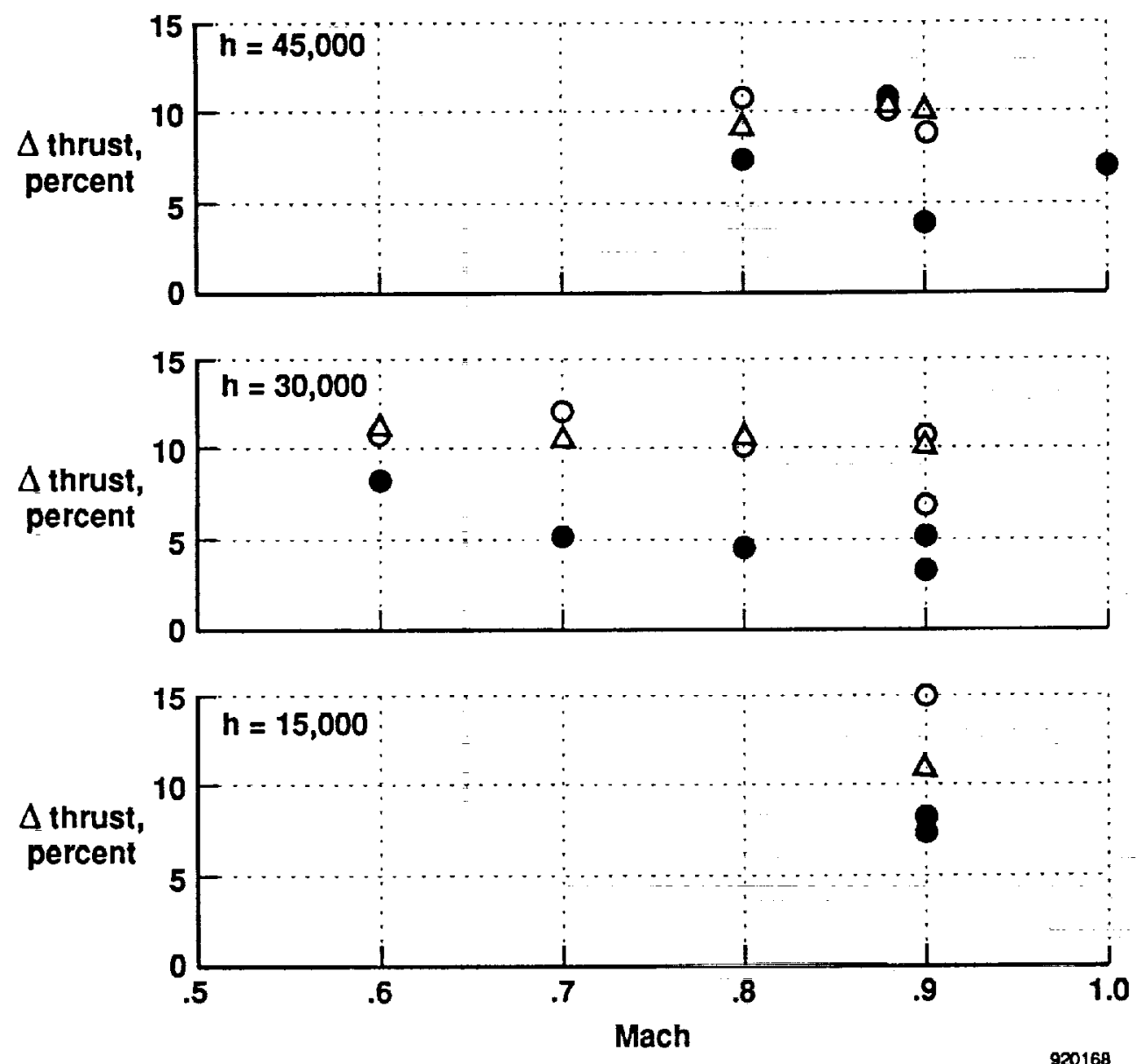

Fig. 9. Predicted and measured thrust increases produced by performance seeking control for refurbished and degraded engines as a function of flight condition.

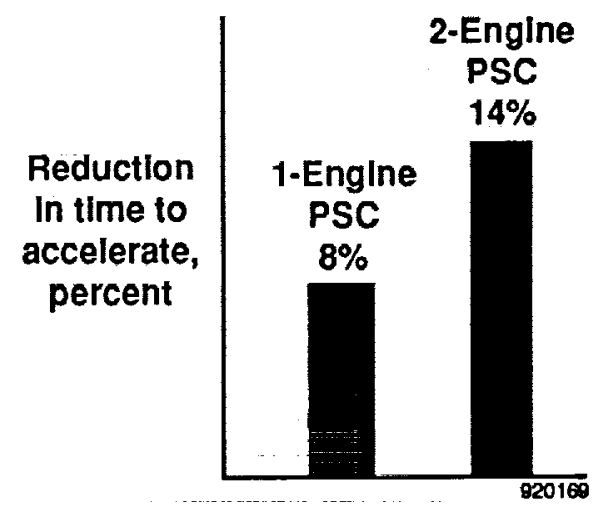

Fig. 10. Comparison of one-engine (measured) and two-engine (extrapolated) performance seeking control results (acceleration from $M=0.50$ to 0.95 at $30,000-\mathrm{ft}$ altitude). 


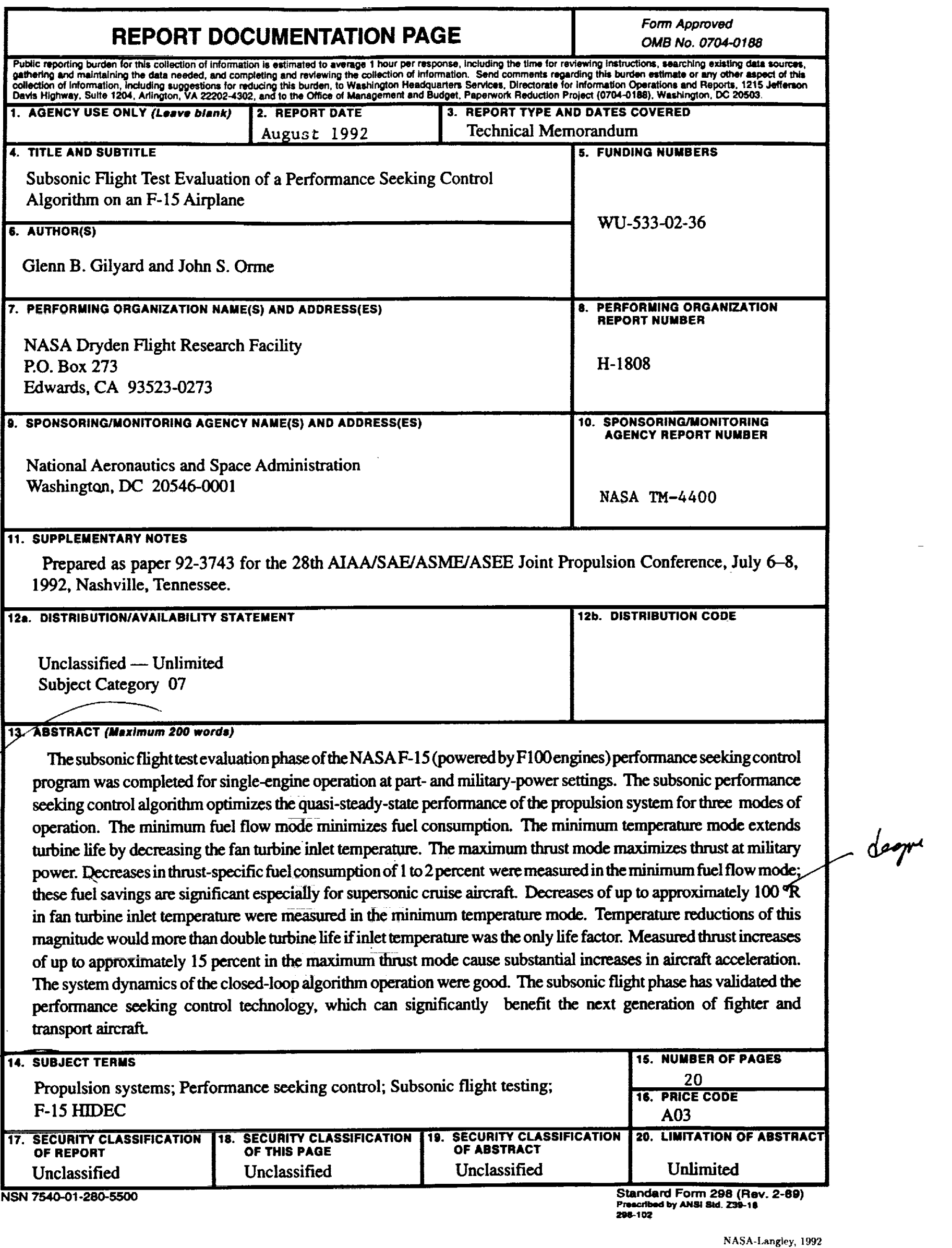

